\title{
Functional mitral regurgitation: structural modifications with percutaneous valve repair with MitraClip
}

\author{
Alberto Alperi ${ }^{1 \#}$, Pablo Avanzas ${ }^{1,2,3 \#}$, Isaac Pascual ${ }^{1,2,4}$, Antonio Adeba ${ }^{1,2}$, Rebeca Lorca ${ }^{1,2}$, Victor León ${ }^{1,2}$, \\ Marcel Almendarez ${ }^{1,2}$, Hector Cubero-Gallego ${ }^{1,2}$, Iria Silva-Conde ${ }^{1}$, César Moris ${ }^{1,2,3}$, \\ Daniel Hernandez-Vaquero ${ }^{1,2,4}$
}

${ }^{1}$ Heart Area, Hospital Universitario Central de Asturias, Oviedo, Spain; ${ }^{2}$ Instituto de Investigación Sanitaria del Principado de Asturias, Oviedo, Spain; ${ }^{3}$ Departamento de Medicina, ${ }^{4}$ Functional Biology Department, University of Oviedo, Oviedo, Spain

Contributions: (I) Conception and design: A Alperi, P Avanzas, D Hernandez-Vaquero, I Pascual; (II) Administrative support: All authors; (III) Provision of study materials or patients: All authors; (IV) Collection and assembly of data: All authors; (V) Data analysis and interpretation: All authors; (VI) Manuscript writing: All authors; (VII) Final approval of manuscript: All authors.

\#These authors contributed equally to this work.

Correspondence to: Isaac Pascual, MD, PhD. Heart Area, Hospital Universitario Central de Asturias, Oviedo, Spain. Email: ipascua@live.com.

Background: Mitral regurgitation (MR) is one of the most prevalent valvular diseases in our society. Transcatheter mitral valve repair (TMVR) with the MitraClip ${ }^{\circledR}$ system is increasingly used for treating this condition. The aim of our study is to analyse morphological mitral valve changes related to the procedure and its correlation with the degree of regurgitation at mid-term follow-up and with the combined endpoint of heart failure and all-cause mortality.

Methods: A single-centre, prospective and observational study including consecutive patients admitted between October 2015 and October 2019 for TMVR was designed. The mitral valve annulus (MVA) was analyzed using the three-dimensional MVQ QLAB mitral valve quantification software (Philips; Amsterdam, The Netherlands). Clinical data was collected retrospectively.

Results: Eighty-two MitraClip ${ }^{\circledR}$ were implanted. Control echocardiograms showed a significant decrease in the three measures: annular diameters, perimeter and area. Patients with functional MR had greater left ventricular and mitral annular dimensions and experienced greater reductions in anteroposterior diameter and mitral valve area compared with organic MR patients. The anteroposterior diameter reduction (OR 0.90; 95\% CI: 0.82-0.99), as well as posterior leaflet grasping (OR 0.94; 95\% CI: 0.89-0.99) were associated with the probability of significant MR recurrence. Posterior leaflet grasping and left ventricle ejection fraction were associated with the combined endpoint of heart failure and any cause death.

Conclusions: MitraClip ${ }^{\circledR}$ implantation results in secondary changes in the mitral annular morphology. The magnitude of these morphological changes varies depending on the etiology of the mitral valve regurgitation. Posterior leaflet grasping and anteroposterior diameter reduction after clip are factors associated with relevant clinical and echocardiographic endpoints.

Keywords: MitraClip; percutaneous; mitral repair; functional; mitral regurgitation (MR)

Submitted Dec 15, 2019. Accepted for publication Feb 27, 2020.

doi: $10.21037 /$ atm.2020.03.45

View this article at: http://dx.doi.org/10.21037/atm.2020.03.45

\section{Introduction}

Mitral valve regurgitation (MR) is considered the second most prevalent valvulopathy in Europe and even the most prevalent one in the United States $(1,2)$. During last years, transcatheter mitral valve repair (TMVR) using the MitraClip ${ }^{\circledR}$ (Abbott Vascular, Menlo Park, California) system has gained increasing interest for treating high or prohibitive surgical risk patients with severe symptomatic 
$M R$, as it implies a less invasive approach. As previously described $(3,4)$, TMVR uses the edge-to-edge technique proposed by Alfieri in order to diminish MR grade. Different studies have proved its efficacy and safety and, recently, a randomized clinical trial has settled robust clinical evidence for its use in symptomatic patients with functional MR (5-8).

TMVR procedure may cause anatomical changes at the level of the mitral valve annulus (MVA) rather than just a simple edge approximation. A previous study suggested relevant changes in the antero-posterior MVA diameter only in functional MR cases (9), while other described global anteroposterior reductions with intercommissural diameter augmentation depending on the etiology of the dysfunction (10).

The aim of our study is to analyse the different morphological changes that take place at the MVA in patients undergoing TMVR, comparing the observations between MR etiologies and relating them to mid-term clinical events.

\section{Methods}

This is a prospective and observational study performed at a tertiary-level hospital.

The aim of our study is to analyse morphological mitral valve changes related to the procedure and its correlation with the degree of regurgitation at mid-term follow-up and with the combined endpoint of heart failure and all-cause mortality.

\section{Patient selection}

All patients with symptomatic, in spite of being under optimal medical therapy, moderate to severe (grade III/ IV) or severe (grade IV/IV) MR were evaluated by a multidisciplinary Heart Team. Patients at high surgical risk and considered optimal for TMVR according to previous anatomical criteria $(4,7)$ were included. Due to the limitations of annular anatomic changes assessment in patients with previous surgical mitral annuloplasty, those patients were excluded for this study. MR was categorized attending to its etiology: primary (organic) or secondary (functional). MR valves with combined etiology were reviewed by two experienced cardiologists in order to classify them into one of the two groups according to its main etiological component. All patients were given proper information about the procedure and signed an informed consent fulfilling Declaration of Helsinki statements.

\section{Percutaneous repair procedure}

All TMVR procedures were performed using the MitraClip ${ }^{\circledR}$ system. This device had already received European conformity (CE mark) in 2018. Procedures were performed transoesophageally echo-guided and under general anaesthesia. Besides, they were all supervised by a technician specialized in MitraClip ${ }^{\circledR}$. Decision regarding more than one clip implantation was taken according to the procedural team judgement. It was considered in those cases where at least one grade in MR decreased was not obtained, as long as the risk of iatrogenic mitral stenosis risk remained reasonably low.

\section{Echocardiographic study}

Before and immediately after all procedures, 2 and 3 dimensional (3D) transoesophageal echocardiograms were performed using the late-generation ultrasound system EPIQ 7 (Philips; Amsterdam, The Netherlands). For this purpose, an extra effort was made to acquire images in similar afterload and haemodynamic conditions both before and after device implantation. Regarding threedimensional MVA evaluation, the 3D images (Zoom 3D, Philips; Amsterdam, The Netherlands) obtained during the procedure were postprocessed with the mitral valve quantification software MVQ QLAB 10.0 (Philips; Amsterdam, The Netherlands).

Leaflet grasping analysis was calculated through the leaflet's length at the deployment plane before and after MitraClip ${ }^{\circledR}$ system implantation. Before clip, leaflet length was measured between the hinge point of the leaflet in the MVA and its free edge, whereas after clip it was measured between the aforementioned hinge point and the most distal leaflet point not yet involved between the clip arms.

Thus, absolute and relative grasping were calculated as follows:

* Absolute grasping (mm): leaflet length pre-clip leaflet length post-clip.

* Relative grasping (\%): [(leaflet length pre-clip leaflet length post-clip)/leaflet length pre-clip] $\times 100$.

\section{Study variables}

\section{Echocardiography}

Technique success, device success and procedural success were defined according to the Mitral Valve Academic Research Consortium (11). Etiology and MR severity were 
evaluated attending to the European Society of Cardiology and Echocardiography guidelines (12-14). Like in EVEREST clinical trial $(4,7)$, severity or MR was classified into 4 different grades. All the measures were performed by only one senior Cardiologist specialist in structural imaging.

\section{Clinical}

Functional status was evaluated by New York Heart Association (NYHA) scale. Heart failure admission was defined as a more than 24 hours hospitalization stay mainly driven by this syndrome. Follow-up main endpoints were MR grade III or IV recurrence and a combined endpoint of heart failure admission and all-cause death.

\section{Statistical analysis}

Categorical variables are represented as absolute number and percentage, whereas quantitative ones as mean \pm standard deviation. T-Student pair test was used for the morphological evaluation of the MVA before and after device deployment. $\mathrm{Xi}$-squared and T-Student test, as applicable, were used for between groups categorical and quantitative comparisons.

Binary logistic regression analysis was performed to evaluate MR grade III or IV recurrence, heart failure admission and death. A 0.05 alpha error was assumed for significance. All analysis has been performed with Stata 14 (Stata Statistical Software: Release 14. College Station, TX: StataCorp LP) software.

\section{Results}

Between October-2015 and October-2019 a total of 82 TMVR using the MitraClip ${ }^{\circledR}$ system were performed, 20 of them (24.4\%) on organic mitral regurgitation (MR) patients and $62(75.6 \%)$ on functional ones. Mean age was $74.7 \pm 7.8$ and $31.7 \%$ were women. Baseline clinical and echocardiographic characteristics of the overall cohort and by etiology comparison are shown in Tables 1 and 2 . Patients with functional MR have larger left ventricular and mitral valve annular dimensions. A total of $1.48 \pm 0.6$ clips were implanted per procedure. First generation clip was used in $43(52.4 \%)$ patients, whereas late-generation clips were deployed in 39 (47.6\%). A 100\% of technical success was accomplished, whereas the procedural success achieved an $89 \%(73 / 82)$. From these nine considered unsuccessful procedures, 6 were due to post-clip MR (4 with grade III and 2 with grade IV), one due to a failed re-intervention and 2 remaining cases presented partial detachment at 3 -month follow-up.

Regarding morphological mitral valve analysis (Table 3), a significant overall reduction in annular diameter, perimeter and area was observed at both the two and three-dimensional analysis. Patients treated for functional MR experienced a greater relative reduction in terms of anteroposterior diameter $(5.5 \% \pm 8.4 \%$ organic $v$. $9.8 \% \pm 8.6 \%$ functional, $\mathrm{P}=0.04)$ and three-dimensional area $(0.4 \% \pm 20.5 \%$ organic vs. $9 \% \pm 13.5 \%$ functional, $\mathrm{P}=0.04)$, as shown in Table 4. Nevertheless, there were no differences between groups in regard to absolute and relative grasping in neither the anterior nor the posterior mitral leaflet.

During a mean follow-up of 484 days (interquartile range, $182-744)$ there were $15(18.3 \%)$ deaths: $5(33.3 \%)$ due to heart failure, $1(6.67 \%)$ because of acute coronary syndrome, 2 (13.3\%) sudden cardiac deaths and 7 (46.67\%) due to non-cardiovascular causes. Nineteen patients $(23.17 \%)$ required hospitalization due to heart failure during follow-up, after procedural discharge. At the binary logistic regression analysis for the primary combined endpoint, after adjustment for different co-variables, left ventricle ejection fraction and relative posterior leaflet grasping were considered significant predictors (Table 5). At the proportional risk cox regression analysis, a trend toward a lower primary endpoint incidence was observed with higher posterior grasping, although without reaching statistical significance (hazard ratio 0.96; 95\% CI: 0.92-1.01; $\mathrm{P}=0.08)$. Figure 1 shows Kaplan-Meier survival function of patients over and under the $50^{\text {th }}$ percentile regarding posterior leaflet grasping percentage.

All patients were followed by periodical echocardiography, having $66(80.5 \%)$ of them completed the 6-month followup transthoracic echocardiogram. From those patients, $10(15.15 \%)$ presented a grade III or IV MR despite clip implantation (Figure 2). Logistic regression analysis searching for anatomical predictors of at least grade III out of IV MR was performed. Both the reduction obtained in anteroposterior mitral annular diameter after clip implantation and the magnitude of posterior leaflet grasping were predictors inversely correlated with a significant MR recurrence (Table 6).

A lineal regression analysis searching for anteroposterior diameter reduction predictors showed that percentual of posterior leaflet grasping was directly associated, maintaining its statistical significance after adjustment by MR etiology, with left ventricular volume, left atrial volume, basal mitral annular dimension and anterior leaflet grasping 
Table 1 Baseline overall cohort and by aetiology characteristics

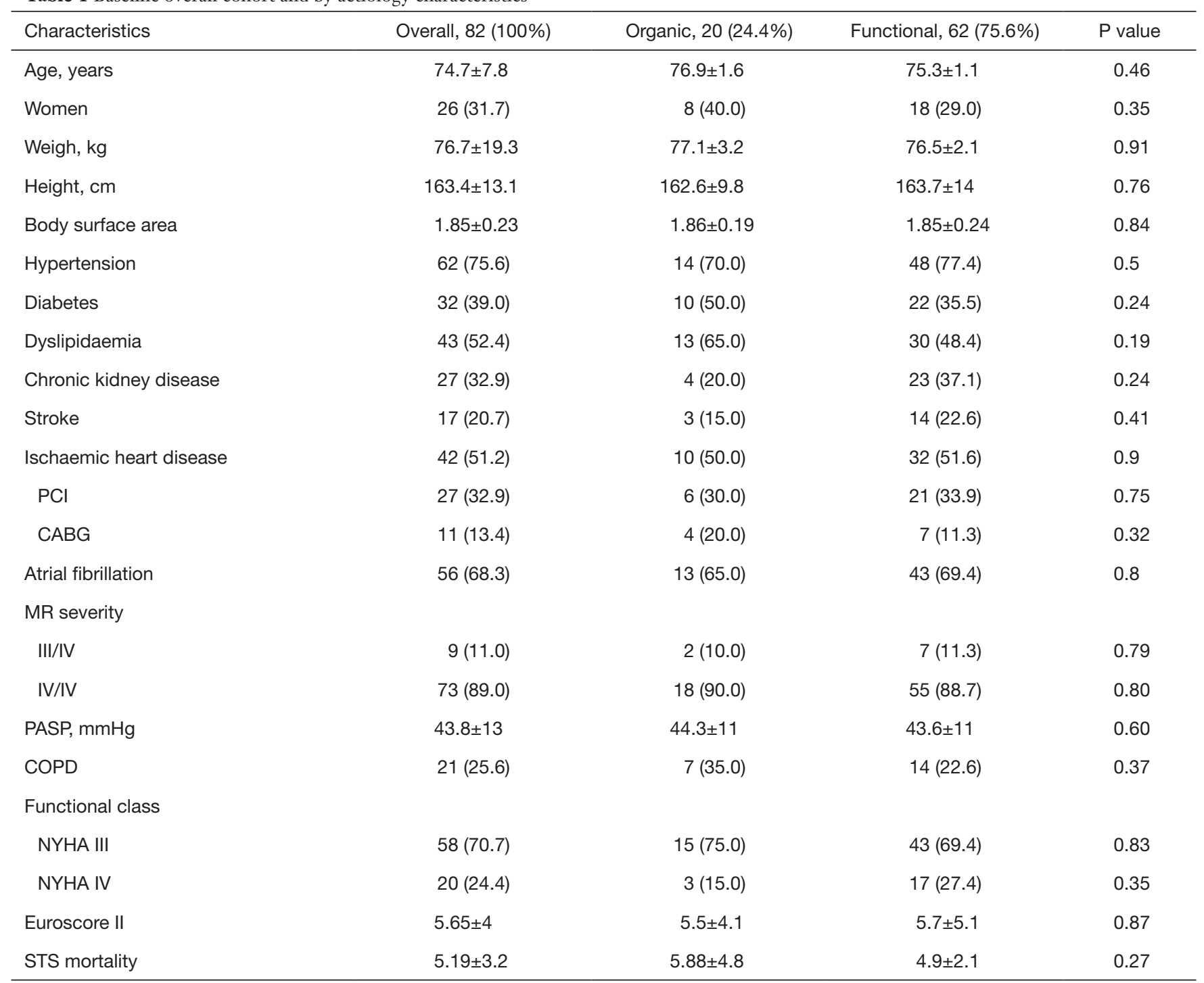

Data are expressed as $\mathrm{n}(\%)$ or mean \pm SD. CABG, coronary artery bypass graft; COPD, Chronic obstructive pulmonary disease; MR, mitral regurgitation; NYHA, New York Heart Association; PASP, pulmonary artery systolic pressure; PCI, percutaneous coronary intervention; STS, Society of Thoracis Surgeons.

( $\beta$ coefficient $=0.17,95 \%$ CI: $0.01-0.32, \mathrm{P}=0.05)$. Hence, greater posterior grasping leads to a higher proportion of anteroposterior diameter reduction.

\section{Discussion}

Our first finding is that after MitraClip ${ }^{\circledR}$ system implantation important anatomical changes are observed at the MVA, either in diameters, perimeters or area. Functional MR valves have larger sizes than the organic ones, in terms of annular measurements (excluding intercommissural diameter). This contrast is understandable based on the different underlying physiopathological mechanism of each condition. Remy et al. reported anteroposterior diameter reduction in the overall cohort, whereas only organic MR patients experienced a significant decrease regarding valve area (10). Other studies conducted exclusively in functional MR valves demonstrated a significant reduction in anteroposterior diameter (10,15-17). A recently published analysis of 60 clip recipients showed significant overall reduction in 
Table 2 Baseline echocardiographic characteristics

\begin{tabular}{|c|c|c|c|c|}
\hline Characteristics & Overall & Organic & Functional & $P$ value \\
\hline iTDLVV, mL/m² & $77.3 \pm 33.3$ & $58.4 \pm 32.4$ & $83.8 \pm 31.2$ & 0.001 \\
\hline iTDLVD, $\mathrm{mm} / \mathrm{m}^{2}$ & $31.5 \pm 6.9$ & $26.6 \pm 7.6$ & $33.2 \pm 5.8$ & 0.001 \\
\hline Index left atrial volume, $\mathrm{mL} / \mathrm{m}^{2}$ & $58.5 \pm 30.6$ & $54.2 \pm 27.7$ & $60.1 \pm 31.7$ & 0.47 \\
\hline Intercommissural diameter, $\mathrm{mm}$ & $39.1 \pm 4.8$ & $38.5 \pm 5$ & $39.3 \pm 4.7$ & 0.52 \\
\hline Anteroposterior diameter, $\mathrm{mm}$ & $38.1 \pm 5.1$ & $36.5 \pm 5.1$ & $38.7 \pm 5$ & 0.05 \\
\hline 2D annular perimeter, mm & $124.2 \pm 14.7$ & $120.7 \pm 17.1$ & $125.3 \pm 13.9$ & 0.12 \\
\hline 3D annular perimeter, $\mathrm{mm}$ & $129.9 \pm 15.8$ & $124.5 \pm 17$ & $131.6 \pm 15.1$ & 0.04 \\
\hline Posterior leaflet length, mm & $13.4 \pm 2.5$ & $13 \pm 2.4$ & $13.5 \pm 2.5$ & 0.12 \\
\hline Tenting length, mm & $10.1 \pm 3.9$ & $7.8 \pm 3.9$ & $10.6 \pm 3.8$ & 0.01 \\
\hline Tenting area, $\mathrm{cm}^{2}$ & $2.47 \pm 1$ & $1.9 \pm 1.2$ & $2.6 \pm 0.9$ & 0.01 \\
\hline
\end{tabular}

Data are expressed as mean \pm SD. 2D, 2 dimensions; 3D, 3 dimensions; ERO, effective regurgitant orifice; iTDLVD, index telediastolic left ventricular diameter; iTDLVV, index telediastolic left ventricular volume antero-posterior; LVEF, left ventricular ejection fraction.

Table 3 Mitral valve annular changes and leaflet grasping

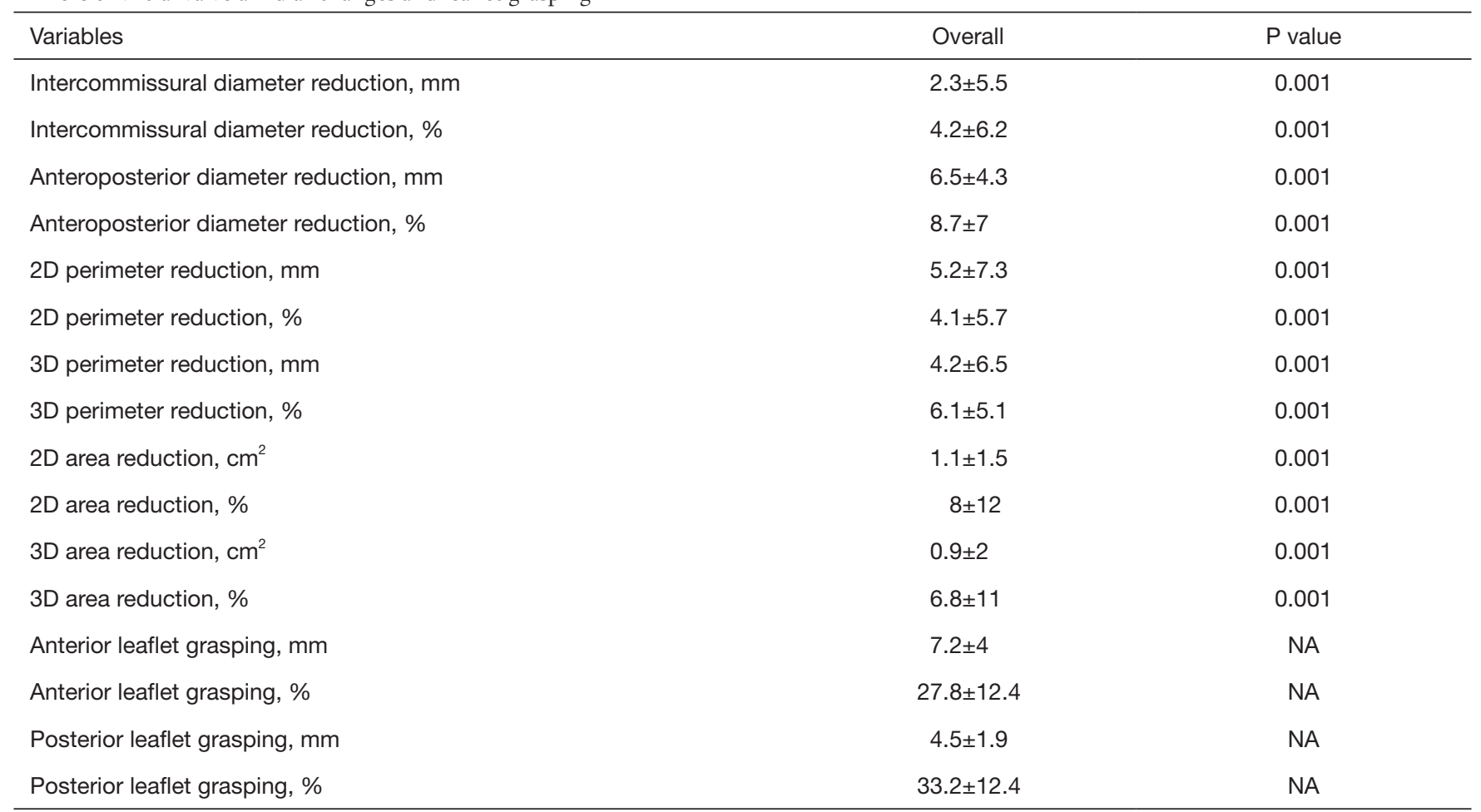

Data are expressed as mean \pm SD. 2D, 2 dimensions; 3D, 3 dimensions; NA, not applicable. 
Table 4 Mitral valve annular change and leaflet grasping comparison among etiologies

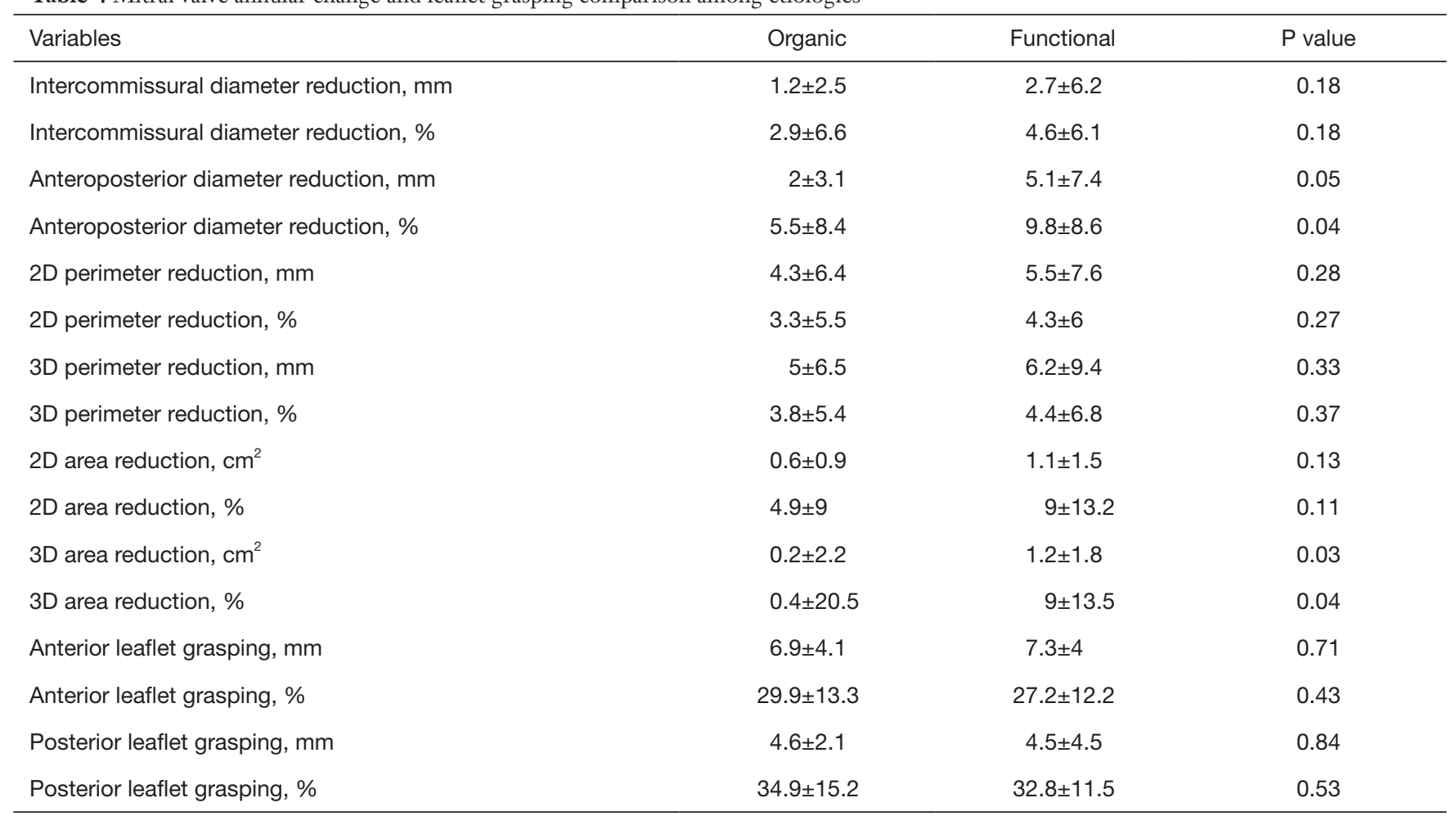

Data are expressed as mean \pm SD. 2D, 2 dimensions; 3D, 3 dimensions.

Table 5 Binary logistic regression for the primary combined endpoint (death-heart failure)

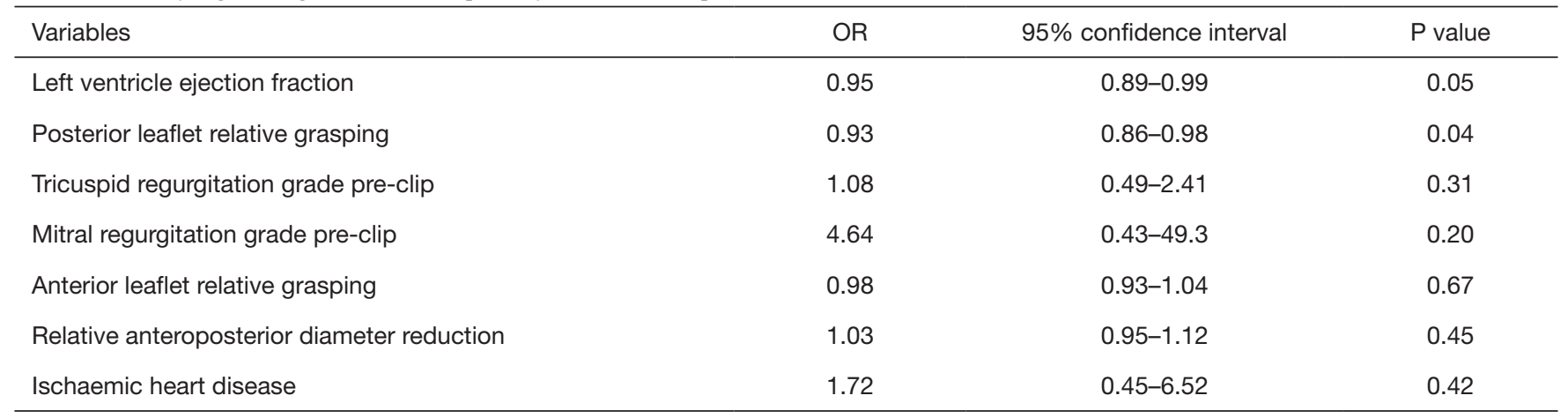

both diameter and perimeter, without differences between etiologies (16). In this study of a larger cohort, we confirmed the global geometrical changes, resulting significant in both etiological groups. However we did find differences between functional and organic valves results. In our cohort, geometrical remodelling after clip seems to be greater in functional MR patients than in organic MR ones.

Moreover, we found an association between the percentual reduction in anteroposterior diameter after procedure and the probability of at least moderate MR recurrence during follow-up. Some previous studies did not associate this finding with any clinical or echocardiographic significant endpoints (16). Hidalgo et al. demonstrated a positive correlation between anteroposterior diameter reduction and effective regurgitant orifice decrease (9). Schueler et al. found that, exclusively in functional MR patients, the anteroposterior diameter reduction was associated with clinical response at 6 months follow-up (15). 


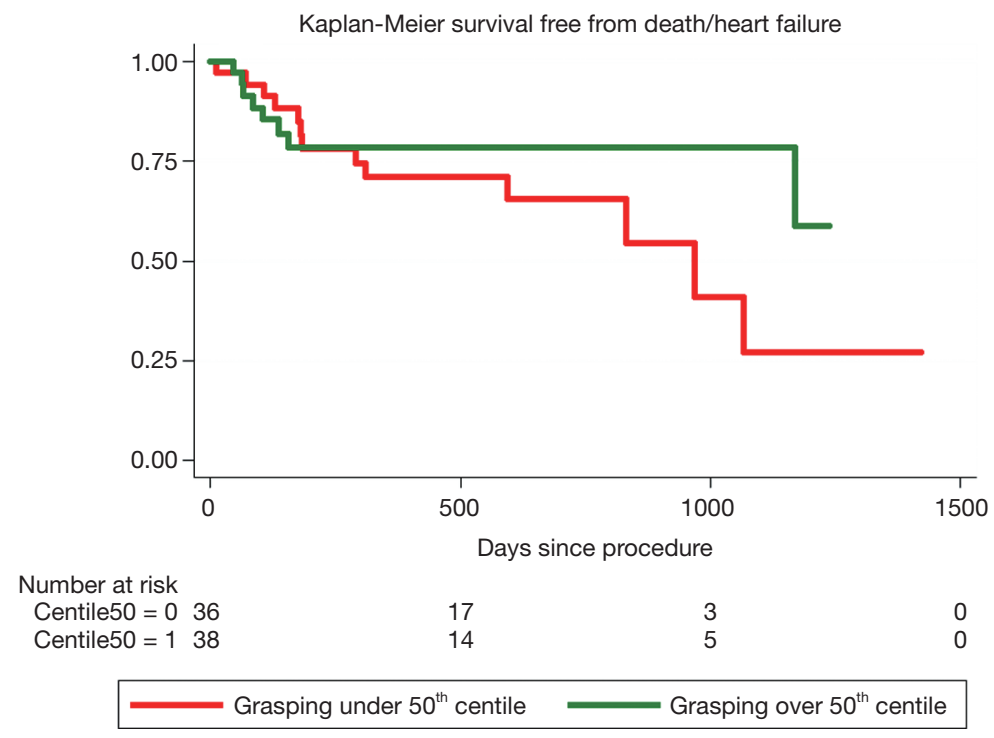

Figure 1 Kaplan-Meier survival function of patients over and under the $50^{\text {th }}$ percentile regarding posterior leaflet grasping percentage.

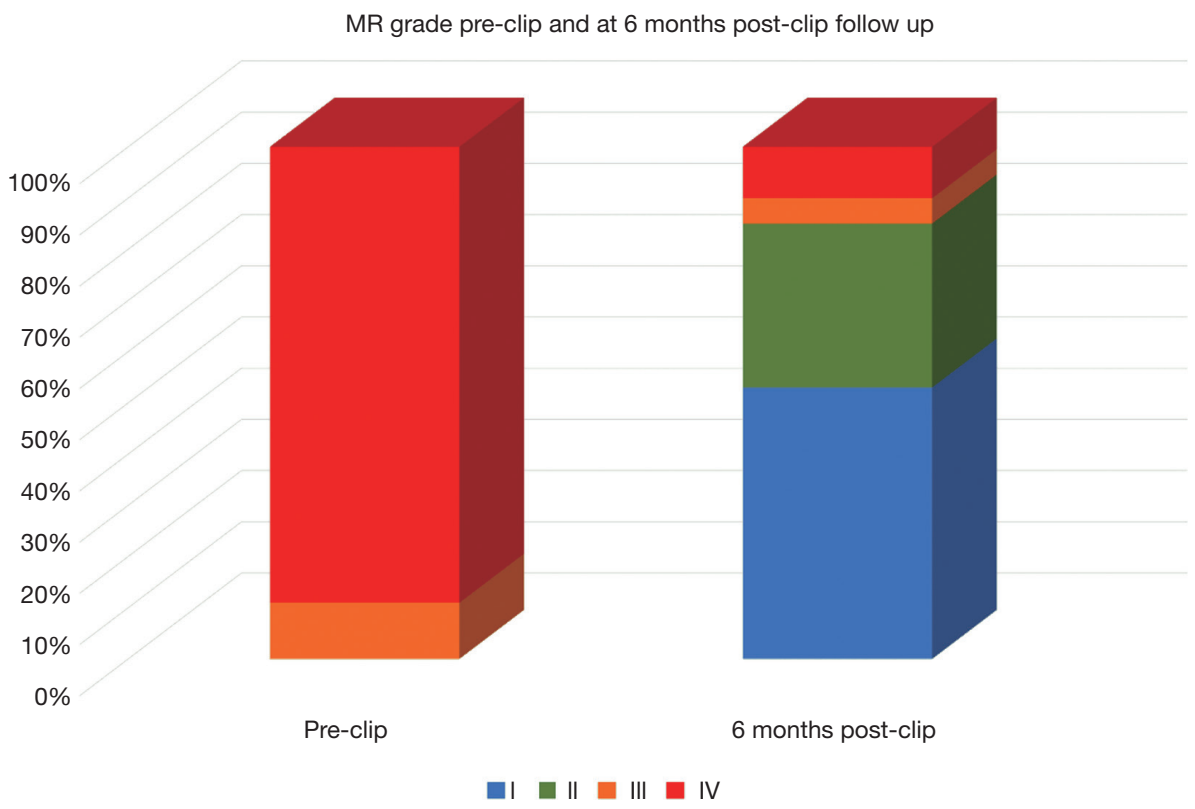

Figure 2 Mitral regurgitation pre-clip and at 6 months of follow-up.

To our knowledge, this is the first study establishing the correlation between anteroposterior diameter reduction and significant echocardiographic endpoints like MR severity at mid-term follow up.

Regarding technical modifiable aspects which may play a role in patients' evolution, we realized that percentual posterior leaflet grasping is a significant landmark to be focused on. This not only predicts the grade of anteroposterior diameter change obtained after clip, but also the MR recurrence. Moreover, it was associated with the main combined endpoint. Regarding to this, we think posterior leaflet grasping should play a key role during the procedure and a goal in the final result, specially in cases with posterior leaflet retraction. 
Table 6 Binary logistic regression for grade III or IV MR at 6-month follow up

\begin{tabular}{|c|c|c|c|}
\hline Variables & OR & $95 \%$ confidence interval & $P$ value \\
\hline Indexed left atrial volume & 0.99 & $0.97-1.02$ & 0.97 \\
\hline Intercommissural diameter reduction & 1.01 & $0.90-1.11$ & 0.97 \\
\hline Anteroposterior diameter reduction & 0.90 & $0.82-0.99$ & 0.04 \\
\hline 3D area reduction & 0.95 & $0.90-1.02$ & 0.15 \\
\hline Anterior leaflet length & 1.01 & $0.84-1.23$ & 0.88 \\
\hline Anterior leaflet grasping & 0.98 & $0.93-1.03$ & 0.42 \\
\hline Posterior leaflet length & 0.96 & $0.75-1.23$ & 0.75 \\
\hline
\end{tabular}

MR, mitral regurgitation; 3D, 3 dimensions.

\section{Limitations}

Our study has different limitations. Firstly, it is an observational study with its inherent probability of bias. Secondly, it is a single-centre analysis, what may preclude general extrapolation of our findings. Regarding this subject, we think that new studies focused on mitral valve morphology and involving a greater number of MitraClip ${ }^{\circledR}$ patients should be encouraged. Thirdly, our number of organic MR patients was modest. Thus, we declined to perform a by-etiology separated search for predictors of MR recurrence or the primary endpoint. Recently, similar prognosis was reported between different etiologies of TMVR patients in a big Spanish cohort (18). Nevertheless it was not focused on mitral valve morphological changes.

The intra-observer variability should be considered in the interpretation of the results.

\section{Conclusions}

MitraClip ${ }^{\circledR}$ implantation results in secondary changes in the mitral annular morphology. The magnitude of these morphological changes varies depending on the etiology of the mitral valve regurgitation. Posterior leaflet grasping and anteroposterior diameter reduction after clip are factors associated with relevant clinical and echocardiographic endpoints.

\section{Acknowledgments}

Funding: None.

\section{Footnote}

Provenance and Peer Review: This article was commissioned by the Guest Editor (Daniel Hernández-Vaquero) for the series "Structural Heart Disease: The Revolution" published in Annals of Translational Medicine. The article was sent for external peer review organized by the Guest Editor and the editorial office.

Conflicts of Interest: All authors have completed the ICMJE uniform disclosure form (available at http://dx.doi. org/10.21037/atm.2020.03.45). The series "Structural Heart Disease: The Revolution" was commissioned by the editorial office without any funding or sponsorship. DHV served as the unpaid Guest Editor of the series and serves as an unpaid editorial board member of Annals of Translational Medicine from Aug 2019 to Jul 2021. The authors have no other conflicts of interest to declare.

Ethical Statement: The authors are accountable for all aspects of the work in ensuring that questions related to the accuracy or integrity of any part of the work are appropriately investigated and resolved. The study was conducted in accordance with the Declaration of Helsinki (as revised in 2013). The study was approved by the corresponding IRB (reference number: 2020/026). Written informed consent was obtained from all patients.

Open Access Statement: This is an Open Access article distributed in accordance with the Creative Commons Attribution-NonCommercial-NoDerivs 4.0 International 
License (CC BY-NC-ND 4.0), which permits the noncommercial replication and distribution of the article with the strict proviso that no changes or edits are made and the original work is properly cited (including links to both the formal publication through the relevant DOI and the license). See: https://creativecommons.org/licenses/by-nc-nd/4.0/.

\section{References}

1. Nkomo VT, Gardin JM, Skelton TN, et al. Burden of valvular heart diseases: a population-based study. Lancet 2006;368:1005-11.

2. Iung B, Baron $\mathrm{G}$, Butchart EG, et al. A prospective survey of patients with valvular heart disease in Europe: The Euro Heart Survey on Valvular Heart Disease. Eur Heart J 2003;24:1231-43.

3. Alfieri O, Maisano F, De Bonis M, et al. The doubleorifice technique in mitral valve repair: a simple solution for complex problems. J Thorac Cardiovasc Surg 2001;122:674-81.

4. Feldman T, Kar S, Rinaldi M, et al. Percutaneous mitral repair with the MitraClip system: safety and midterm durability in the initial EVEREST (Endovascular Valve Edge-to-Edge REpair Study) cohort. J Am Coll Cardiol 2009;54:686-94.

5. Puls M, Lubos E, Boekstegers P, et al. One-year outcomes and predictors of mortality after MitraClip therapy in contemporary clinical practice: results from the German transcatheter mitral valve interventions registry. Eur Heart J 2016;37:703-12.

6. Maisano F, Franzen O, Baldus S, et al. Percutaneous mitral valve interventions in the real world: early and 1-year results from the ACCESS-EU, a prospective, multicenter, nonrandomized post-approval study of the MitraClip therapy in Europe. J Am Coll Cardiol 2013;62:1052-61.

7. Feldman T, Foster E, Glower DD, et al. Percutaneous repair or surgery for mitral regurgitation. N Engl J Med 2011;364:1395-406.

8. Stone GW, Lindenfeld J, Abraham WT, et al. Transcatheter Mitral-Valve Repair in Patients with Heart Failure. N Engl J Med 2018;379:2307-18.

9. Hidalgo F, Mesa D, Ruiz M, et al. Effects of Mitral Annulus Remodeling Following MitraClip Procedure on Reduction of Functional Mitral Regurgitation. Rev Esp Cardiol (Engl Ed) 2016;69:1020-5.

10. Remy T, Bertog SC, Wunderlich N, et al. Change in mitral annular size and geometry after MitraClip ${ }^{\circledR}$ implantation in patients with functional and degenerative mitral regurgitation. J Interv Cardiol 2014;27:516-24.

11. Stone GW, Adams DH, Abraham WT, et al. Clinical Trial Design Principles and Endpoint Definitions for Transcatheter Mitral Valve Repair and Replacement: Part 2: Endpoint Definitions: A Consensus Document From the Mitral Valve Academic Research Consortium. J Am Coll Cardiol 2015;66:308-21.

12. Flachskampf FA, Wouters PF, Edvardsen T, et al. Recommendations for transoesophageal echocardiography: EACVI update 2014. Eur Heart J Cardiovasc Imaging 2014;15:353-65.

13. Lancellotti P, Tribouilloy C, Hagendorff A, et al. Recommendations for the echocardiographic assessment of native valvular regurgitation: an executive summary from the European Association of Cardiovascular Imaging. Eur Heart J Cardiovasc Imaging 2013;14:611-44.

14. Baumgartner H, Falk V, Bax JJ, et al 2017 ESC/EACTS Guidelines for the management of valvular heart disease. Eur Heart J 2017;38:2739-91.

15. Schueler R, Momcilovic D, Weber M, et al. Acute changes of mitral valve geometry during interventional edgeto-edge repair with the MitraClip system are associated with midterm outcomes in patients with functional valve disease: preliminary results from a prospective singlecenter study. Circ Cardiovasc Interv 2014;7:390-9.

16. Donmez E, Salcedo EE, Quaife RA, et al. The acute effects of edge-to-edge percutaneous mitral valve repair on the shape and size of the mitral annulus and its relation to mitral regurgitation. Echocardiography 2019;36:732-41.

17. Noack T, Kiefer P, Mallon L, et al. Changes in dynamic mitral valve geometry during percutaneous edgeedge mitral valve repair with the MitraClip system. J Echocardiogr 2019;17:84-94.

18. Pascual I, Arzamendi D, Carrasco-Chinchilla F, et al. Transcatheter mitral repair according to the cause of mitral regurgitation: Real-life data from the Spanish MitraClip registry. Rev Esp Cardiol (Engl Ed) 2019. [Epub ahead of print].

Cite this article as: Alperi A, Avanzas P, Pascual I, Adeba A, Lorca R, León V, Almendarez M, Cubero-Gallego H, SilvaConde I, Moris C, Hernandez-Vaquero D. Functional mitral regurgitation: structural modifications with percutaneous valve repair with MitraClip. Ann Transl Med 2020;8(15):958. doi: 10.21037/atm.2020.03.45 